Environmental Science and Pollution Research

May 2017, Volume 24, Issue 15, Pages 13797-13807

http://dx.doi.org/10.1007/s11356-017-8972-y

http://archimer.ifremer.fr/doc/00382/49330/

(C) Springer-Verlag Berlin Heidelberg 2017

\title{
In situ measurement with diffusive gradients in thin films: effect of biofouling in freshwater
}

\author{
Uher Emmanuelle ${ }^{1,2,{ }^{*} \text {, Compère Chantal }}{ }^{3}$, Combe Matthieu ${ }^{1}$, Mazeas Florence ${ }^{3}$, \\ Gourlay-Francé Catherine ${ }^{1,2,4}$
}

${ }^{1}$ Irstea, UR HBAN Hydrosystèmes et BioprocédésAntony Cedex,France

${ }^{2}$ FIRE FR-3020Paris,France

3 IFREMER, Centre de Bretagne, ZI de la Pointe du DiablePlouzané,France

${ }^{4}$ AnsesMaisons-Alfort Cedex,France

*Corresponding author : Emmanuelle Uher, email address : emmanuelle.uher@irstea.fr

\begin{abstract}
:
Concerning in situ passive sampler deployment, several technical priorities must be considered. In particular, deployment time must be sufficiently long not only to allow a significant quantity to be accumulated to facilitate analysis but also to ensure that the signal is above the quantification limit and out of the blank influence. Moreover, regarding the diffusive gradient in thin films (DGT) technique, deployment time must also be sufficiently long (at least 5 days) to avoid the interactions of the solutes with the material diffusion layer of the DGT and for the steady state to be reached in the gel. However, biofouling occurs in situ and modifies the surface of the samplers. In this article, we propose a kinetic model which highlights the biofouling effect. This model was able to describe the mitigation of the flux towards the DGT resin observed on $\mathrm{Cd}$, Co, Mn, Ni and $\mathrm{Zn}$ during a 22-day deployment in the Seine River. Over a period of 22 days, biofouling had a significant impact on the DGT concentrations measured, which were decreased twofold to threefold when compared to concentrations measured in unaffected DGTs.
\end{abstract}

Keywords : DGT, Metals, Biofouling, Seine River, Field deployment, Passive sampler 


\section{Introduction}

23 Passive samplers are an emerging way of assessing water quality. Their use is increasing in the scientific

24 community. It is claimed that they provide time-integrated concentrations of the species they measure during their

25 deployment in water. Quantification limits are lowered and the matrix effects in the analytical process are reduced.

26 However, in situ conditions differ significantly from convenient laboratory conditions. Biofouling occurs at the

27 surface of the samplers being immersed in water. In freshwater, physicochemical conditions differ greatly between

28 sampling sites, while deployment time is subjected to many constraints: metal accumulation must be significant,

29 whereas, in relatively uncontaminated sites, this may require a long deployment time, and interactions of the solutes

30 with the material diffusion layer cannot be neglected if the deployment time is too short. Diffusion of metals may be

31 retarded at the beginning of the deployment because of these interactions, and deployment time has to be sufficiently

32 long to ensure the steady state is reached, as is discussed by Davison and Zhang (2012) and Garmo et al. (2008b,a).

33 Previous studies examined what consequences the presence of major ions had on diffusive gradient in thin film 34 (DGT) measurements in marine water (Tankere-Muller et al. 2012). They also simulated the limits of the linear 35 accumulation regime of DGT concerning $\mathrm{pH}$, deployment time, and dissolved ligands (Mongin et al. 2013). Others 36 studies showed that biofouling might affect DGT measurement: Pichette et al. (2007) and Feng et al. (2016) studied 37 the effect of biofilm development on phosphate measurement using DGT, respectively in a freshwater aquaculture 38 pond and in freshwater. It has already been observed that biofouling had a strong effect on DGT measurement in 39 raw wastewater (Uher et al. 2012). However, Buzier et al. showed that 14-day-biofouling did not affect the diffusion 40 coefficient of the DGT diffusion layer in freshwater (Buzier et al. 2014).

41 Biofilm developing at the surface of DGT has long been suspected to behave as an additional inert diffusion layer, 42 which may reduce the uptake of the species analyzed (Booij et al. 2006, Pichette et al. 2007, Schafer et al. 2008). 43 Moreover, it has long been known that biofilm interacts with metals in solution through various processes (Van 44 Hullebusch et al. 2003). One of these processes, biosorption on biofilms and bacterial cells has been studied in depth 45 as a potential sorbing material for removing metals from waste solutions (Ginisty et al. 1998, Kuyucak and Volesky 46 1988, Veglio and Beolchini 1997, Wase and Wase 2002). Other interactions of varying importance and reversibility 
may occur between biofilm and metals, namely: complexation, precipitation of insoluble salts, adsorption on iron and manganese oxides, and reduction, as highlighted both in a comprehensive review by Van Hullebusch et al. (2003) of knowledge of the mechanisms of metal immobilization by biofilm and also in several experimental studies conducted under varying conditions and with several metals (Bradac et al. 2009a, Bradac et al. 2010, Duong et al. 2010, Faburé et al. 2015, Fechner et al. 2014, Moppert et al. 2009, Toner et al. 2005, White and Gadd 2000). It is also assumed that biofilm is a "gateway" between dissolved metals in solution and hydrous metal oxides coating the streambed, and that biofilm plays a role in the diel cycles of dissolved metals (Nimick et al. 2011). More recent reviews have focused on the role of extracellular polymeric substances (EPSs, secreted by microorganisms), which exhibit abundant binding sites for metals ( $\mathrm{Li}$ and $\mathrm{Yu}$ 2014, More et al. 2014). Feng et al. showed that the composition of a biofilm grown at the surface of DGT phosphate-samplers mainly consisting of diatoms, several metal oxides (Fe, Al, Mn) and EPSs (Feng et al. 2016). Buzier et al.(2014) also observed biofilm forming at the surface of DGT samplers: biofilm was composed of organic deposits and metallic oxides capable of adsorbing species.

The results of our previous study suggest that biofilms at the surface of DGTs and metal species interact (Uher et al. 2012). Different effects were observed depending on the metal being studied ( $\mathrm{Cd}, \mathrm{Cr}, \mathrm{Co}, \mathrm{Cu}, \mathrm{Mn}, \mathrm{Ni}, \mathrm{Pb}, \mathrm{Zn})$. It was concluded from these results that biofilm exhibits metal-binding properties with varying degrees of specificity and affinity, depending on the metal under scrunity. Furthermore, the literature suggests that metal-binding properties also depend on the bulk solution chemistry and on the physiological state of the biofilm (Nimick et al. 2011). The biofilm's composition is likely to vary according to the sampling site and deployment conditions. Thus, biofouling can also be expected to vary with the sampling site. A simple kinetic model which highlights the physicochemical interactions between metals and biofilms was proposed to explain biofilm's effect on DGT measurement. However, we need to precisely verify whether the description we proposed is valid in other conditions than in wastewater where the former experiments were conducted. DGTs are more often deployed in freshwater. Therefore more freshwater data are needed to establish a model of the impact of biofouling on DGT measurement.

The first purpose of this particular research was to precisely describe how biofouling may affect the transfer of metals to the DGT chelating resin by proposing a quantitative model involving physicochemical interactions of metals and biofilm. Its second purpose was to verify whether this hypothesis is valid in freshwater. A study was 
conducted in the Seine River. Accumulation of metals in the DGT Chelex resin was monitored along with biofouling and biomass growth estimation of the biofilm attached to the protective membrane of the DGT, in order

$J=\frac{m}{t A}$ to compare the model with the experimental data. Physicochemical conditions and deployment time were considered while discussing the results.

\section{Theoretical background}

\subsection{DGT principle}

The principle of DGT is based on Fick's first law. DGTs are composed of a chelating resin, a diffusive hydrogel, and a protective membrane. A metal diffusion gradient develops between the bulk solution and the resin layer because this latter strongly sequesters cationic metals. Consequently, metal species are transported through the material diffusion layer (MDL), comprising of the gel and the membrane, toward the resin. The flux (J) of metal ions can be expressed by Equation 1:

$\mathrm{J}=\mathrm{D}_{\mathrm{MDL}} \frac{\Delta \mathrm{C}}{\Delta_{\mathrm{MDL}}}$

where $\mathrm{D}_{\mathrm{MDL}}$ is the diffusion coefficient in the material diffusion layer, $\Delta \mathrm{C}$ is the concentration gradient, and $\Delta_{\mathrm{MDL}}$ is the thickness of the MDL. The free metal ions in the diffusion layer are in rapid equilibrium with the resin, so the concentration near the resin is zero. $\Delta \mathrm{C} \approx \mathrm{C}$, where $\mathrm{C}$ is the concentration in the bulk solution. Therefore at steady state Equation 1 becomes:

$\mathrm{J}=\mathrm{D}_{\mathrm{MDL}} \frac{\mathrm{C}}{\Delta_{\mathrm{MDL}}}$

Equation 2

The flux of species through an area (A) after a given time $(\mathrm{t})$ is also defined by:

Equation 3

where $\mathrm{m}$ is the mass of metal accumulated in the chelating resin. It should be noted that $\mathrm{J}$ is the mean flux of the

91 metals during the deployment time.

92 Combining Equation 2 and Equation 3 shown above, the equation giving the concentration in water measured by 93 DGT is as follows:

$$
\mathrm{C}_{\mathrm{DGT}}=\frac{\mathrm{m} \Delta_{\mathrm{MDL}}}{\mathrm{D}_{\mathrm{MDL}} \mathrm{tA}}
$$


As soon as a substrate is immersed in water, planktonic cells would attach and, through growth and EPS production, biofilms may develop. This biofilm layer both constitutes an additional diffusion layer for DGT and exhibits abundant interaction sites for metals. However, DGT cannot be considered as just any surface in water because of the affinity of metal for chelating resin thereby creating the diffusion gradient in the gel of the DGT device. Thus metals fate may be driven by two different sinks: the diffusion through the DGT gel because of the resin and the binding within the external biofilm. This is illustrated in Figure 1: whenever metals interact with or within the biofilm matrix, they are temporarily fixed by the biofilm. Metals reversibly retained by the biofilm eventually diffuse through the hydrogel toward the resin. If the dissociation of the metal from the biofilm is the limiting step, metal diffusion in the hydrogel might be severely retarded. If the complexes dissociate readily, accumulation of metal in the resin might occur with no significant effect.

Two parameters are decisive: firstly the nature of the biofilm which in turn may alter the nature of the interactions with the metals and secondly the metal concentration in water which influences the diffusion gradient force. in water is constant. When a part of the metal is retained by the biofilm, the mean flux $\mathrm{J}$ should be reduced to account for that part that does not diffuse because of interactions:

$\mathrm{J}=\mathrm{J}_{0}-\mathrm{D}_{\mathrm{MDL}} \frac{\overline{\mathrm{C}_{\mathrm{B}}}}{\Delta_{\mathrm{MDL}}}$

111 where $\mathrm{J}_{0}$ is the flux in the absence of biofilm and $\overline{\mathrm{C}_{\mathrm{B}}}$ is the mean metal concentration immobilized in the biofilm 112 during the deployment time in $\mathrm{ng} \mathrm{cm}^{-3}$.

113 Given the reactions shown in Figure 1, the kinetics of metal in the biofilm can be described by Equation 6:

$\frac{\mathrm{dC}_{\mathrm{B}}}{\mathrm{dt}}=\mathrm{k}_{1} \mathrm{C}_{\mathrm{M}}-\mathrm{k}_{2} \mathrm{C}_{\mathrm{B}}$

114 where $C_{B}$ is the concentration of metal immobilized in the biofilm and $C_{M}$ is the concentration of metal $M$ 115 interacting with biofilm in water in the vicinity of the sampler. Considering $C_{B}=0$ at time $t=0$, we deduce Equation 1167 by integrating Equation 6: 
$\mathrm{C}_{\mathrm{B}}(\mathrm{t})=\mathrm{C}_{M} \frac{\mathrm{k}_{1}}{\mathrm{k}_{2}}\left(1-\mathrm{e}^{-\mathrm{k}_{2} \mathrm{t}}\right)$

Equation 7

where $k_{1}$ is the uptake rate of metal in the biofilm $\left(\mathrm{d}^{-1}\right)$, and $\mathrm{k}_{2}$ is the elimination rate constant $\left(\mathrm{d}^{-1}\right)$. Equation 7 corresponds to a two-compartment kinetic model (Landrum et al. 1992) where $\mathrm{k}_{1}$ is considered as a constant under the assumption that the free binding sites concentration is in large excess compared to $\mathrm{C}_{\mathrm{M}}$. Former studies used this type of model to describe the accumulation of metal in biofilm (Bradac et al. 2009, Hill and Larsen 2005). $\mathrm{C}_{\mathrm{B}}(\mathrm{t})$ is rigorously the metal concentration in the biofilm at a given time t. Here the mean metal concentration in the biofilm between 0 and $t\left(\overline{C_{B}}\right.$ in Equation 5) is approximated to $C_{B}(t)$ for every $t$.

Combining Equation 5 and Equation 7 gives the following Equation 8:

$$
\begin{aligned}
& \mathrm{J}=\mathrm{J}_{0}-\mathrm{C}_{\mathrm{M}} \frac{\mathrm{D}_{\mathrm{MDL}}}{\Delta_{\mathrm{MDL}}} \frac{\mathrm{k}_{1}}{\mathrm{k}_{2}}\left(1-\mathrm{e}^{-\mathrm{k}_{2} \mathrm{t}}\right) \\
& \mathbf{J}=\mathbf{J}_{\mathbf{0}}-\alpha\left(\mathbf{1}-\mathbf{e}^{-\beta \mathbf{t}}\right)
\end{aligned}
$$

Equation 9

Where $\alpha=C_{M} \frac{D_{M D L}}{\Delta_{M D L}} \frac{k_{1}}{k_{2}} \quad$ and $\quad \beta=k_{2}$

Equation 10

\section{Experimental section}

Twenty-four DGTs equipped with restricted gels (acrylamide with $0.8 \%$ bis-acrylamide cross-linker) and protective membranes: polyethersulfone-PES $(0.45 \mu \mathrm{m}$ pore diameter, $2.5 \mathrm{~cm}$ diameter, $140 \mu \mathrm{m}$ thickness, Pall, Port Washington, New York, USA), and twenty-four DGTs equipped with restricted gels, protective membranes PES and Polycarbonate nuclepore membranes PC $(0.4 \mu \mathrm{m}$ pore diameter, $2.5 \mathrm{~cm}$ diameter, $10 \mu \mathrm{m}$ thickness, Whatman, Little

130 Chalfont, UK) were deployed in the Seine River, $40 \mathrm{~km}$ upstream of Paris, from $27^{\text {th }}$ March 2012 to $18^{\text {th }}$ April 2012.

131 Accumulation of metals in Chelex resin was followed for 22 days by retrieving 6 DGTs of each type (PES and PC)

132 at $\mathrm{t}=3,8,15$, and 22 days (Figure 2). New triplicates of DGT of each type were deployed between: $\mathrm{t}=3$ and $\mathrm{t}=8, \mathrm{t}=8$ 133 and $\mathrm{t}=15, \mathrm{t}=15$ and $\mathrm{t}=22$.

134 To measure total dissolved concentrations, two grab samples were collected with a plastic needle and filtered in situ 135 (Minisart syringe filters with PES membranes, $0.45 \mu \mathrm{m}$, Sartorius, Göttingen, Germany) at time 3, 8, 15, and 22 136 days. Samples were acidified $1 \%$ vol. using suprapur $\mathrm{HNO}_{3}(65 \%$ suprapur, Merck, Darmstadt, Germany) in the laboratory. 
138 Moreover, grab samples were collected and filtered in situ to measure major ions $\left(\mathrm{Ca}^{2+}, \mathrm{Mg}^{2+}, \mathrm{K}^{+}, \mathrm{Na}^{+}, \mathrm{NO}_{3}^{-}, \mathrm{Cl}^{-}\right.$,

$139 \mathrm{SO}_{4}{ }^{2-}, \mathrm{PO}_{4}{ }^{3-}, \mathrm{CO}_{3}{ }^{2-}$ ) and also the dissolved organic carbon (DOC). $\mathrm{pH}$, temperature were measured in situ. The data

140 collected may be examined in the supporting information (Table SI 1).

\subsection{DGT treatment}

142 DGTs retrieved at time 3, 8, 15, and 22 days were dismantled and metals were eluted from the Chelex resin by 143 soaking it in $\mathrm{HNO}_{3} 1 \mathrm{~mol} \mathrm{~L}{ }^{-1}$. PES and PC membranes were frozen $\left(-80^{\circ} \mathrm{C}\right)$.

145 To estimate the mass of deposits on membranes, the total carbon (TC) was analyzed using a LECO CS 125 analyser

146 (St. Joseph, MI, USA) with a combustion of $900^{\circ} \mathrm{C}$. Coupons $(1 \mathrm{~cm} \times 1 \mathrm{~cm})$ were cut from protective membranes of 147 DGT after exposure (at least three coupons for each immersion condition). Each coupon was immersed in $20 \mathrm{~mL}$ 148 pure sterilized water and placed in an ultrasonic bath for 40 mins to remove the deposit. The sonication was stopped 149 regularly and the water in the bath replaced with cold water to prevent the samples from overheating. Then the 150 solution was filtered on a weighted and precombusted $\left(4 \mathrm{hrs}, 450^{\circ} \mathrm{C}\right)$ filter in fibreglass $(\mathrm{GF} / \mathrm{F}$, Whatman; diameter, $1512 \mathrm{~cm}$ ). The fibreglass filter was dried in a laboratory oven at $37^{\circ} \mathrm{C}$ overnight and then placed in a ceramic crucible 152 directly in the furnace for combustion; accelerators (iron and tungsten) were required.

153 The biofilm attached to these membranes was observed by scanning electron microscopy (SEM). After exposure, the 154 protective DGT membranes were rinsed in baths of pure water and then dehydrated under a formalin atmosphere in 155 a fume hood; the surfaces were covered with a thin layer of gold/palladium prior to SEM imaging. All samples were 156 imaged in an FEI Quanta 200 scanning electron microscope. 3.4 Metal analysis

158 Metals from DGTs and grab samples were analyzed using the ICP-MS (X series 2 Thermo Fisher Scientific, 159 Villebon-sur-Yvette, France). Calibration of the ICP-MS was verified by analysis of the certified reference material 160 NIST 1640a (natural water): mean recovery $=98 \%$. 
163 Equation $3\left(\mathbf{J}=\frac{\mathbf{m}}{\mathbf{t A}}\right)$ was used to calculate the mean flux at time $\mathrm{t}$, with $\mathrm{m}$ as the mass of metal accumulated on the 164 resin at $\mathrm{t}$ and with $\mathrm{A}$ as the exposure area. The calculated flux $\mathrm{J}$ was plotted against $\mathrm{t}$. The effective sampling area $\mathrm{A}_{\mathrm{e}}$ taking into account lateral diffusion was used in the calculations. $\mathrm{A}_{\mathrm{e}}$ was taken equal to $3.66 \mathrm{~cm}^{2}$, according to Knutsson et al. (2014).

\subsection{Labile concentration calculation}

168

$\mathrm{C}_{\mathrm{DGT}}=\frac{\mathrm{m}}{\mathrm{tA}_{\mathrm{e}}}\left(\frac{\Delta_{\mathrm{MDL}}}{\mathrm{D}_{\mathrm{MDL}}}+\frac{\delta}{\mathrm{D}_{\mathrm{W}}}\right)=\mathrm{J}\left(\frac{\Delta_{\mathrm{MDL}}}{\mathrm{D}_{\mathrm{MDL}}}+\frac{\delta}{\mathrm{D}_{\mathrm{W}}}\right)$ free metal in water is $\mathrm{D}_{\mathrm{W}}$. Equation 4 becomes:

Previous studies showed that a diffusion boundary layer $\delta$ is created in front of the samplers when they are immersed in water (Garmo et al. 2006, Uher et al. 2013, Warnken et al. 2006). $\delta$ has to be taken into account in the calculations where possible. $\delta$ is considered as an additional diffusion layer where the diffusion coefficient of the

When a linear relationship between the mass accumulated on the resin $\mathrm{m}$ and the time $\mathrm{t}$ exists, the slope of the linear model can be used to calculate a global labile concentration as follows:

$\mathrm{C}_{\mathrm{DGT}}=\frac{\text { slope }}{\mathrm{A}_{\mathrm{e}}}\left(\frac{\Delta_{\mathrm{MDL}}}{\mathrm{D}_{\mathrm{MDL}}}+\frac{\delta}{\mathrm{D}_{\mathrm{W}}}\right)$ Equation 12

174 The diffusion coefficients $\mathrm{D}_{\mathrm{MDL}}$ used in this study were calculated in a previous study where we showed that 175 protective membranes had no influence on the overall diffusion coefficient of the diffusion layer with restricted gels 176 (Uher et al. 2012). $\mathrm{D}_{\mathrm{W}}$ were taken from Li et al. (1974). $\mathrm{D}_{\mathrm{MDL}}$ and $\mathrm{D}_{\mathrm{W}}$ were corrected for the in situ temperature 177 according to Zhang and Davison (1995).

178 The flow rate in the Seine River was high $\left(109 \pm 10 \mathrm{~m}^{3} \mathrm{~s}^{-1}\right)$. No significant precipitations occurred and the flow rate remained fairly stable during the deployment, so the diffusive boundary layer thickness $\delta$ was taken to be constant

180 over the deployment. As we dealt with fast-flowing water $\delta$ was set at $0.026 \mathrm{~cm}$, as calculated in our previous study 181 (Uher et al. 2013). 
184 Fluxes $\mathrm{J}$ according to the time were calculated for DGTs deployed at $\mathrm{d}=0$. The models described in the theoretical background were fitted to the experimental data using nonlinear regression of the XLStat $@$ software. $J_{0}, \alpha$ and $\beta$ are

186 the regression coefficients of the nonlinear model. Limits of the model were calculated with the limit values of the $95 \%$ confidence intervals of the parameters: upper limit $=\mathrm{J}$ calculated with $\mathrm{J}_{0 \max }, \alpha_{\min }, \beta_{\min }$, lower limit $=\mathrm{J}$ calculated with $\mathrm{J}_{0 \min }, \alpha_{\max }, \beta_{\max }$.

\section{Results and discussion}

\subsection{Dissolved metal concentration}

Total dissolved concentrations in $\mathrm{Cr}, \mathrm{Co}, \mathrm{Cu}, \mathrm{Mn}, \mathrm{Ni}, \mathrm{Pb}$, and $\mathrm{Zn}$ measured from day 0 (first day of the deployment) to day 22 are represented in Figure SI 1. Total dissolved concentrations were fairly stable over time, except for $\mathrm{Cu}$, which increased at time $\mathrm{t}=3$ and $\mathrm{t}=5$ days, and for $\mathrm{Zn}$. A discrepancy between the replicates was also observed: $40 \%$ for $\mathrm{Cr}$ at $\mathrm{d} 3$ and $\mathrm{d} 15,30 \%$ for $\mathrm{Mn}$ at $\mathrm{d} 22$.

\subsection{Biofilm growth at the surface of the membranes}

The total carbon measured on the membranes' surface over time is represented in Figure 3. The mass of carbon clearly increased with time, indicating that the biofilm grew steadily during the deployment. This result is supported by the SEM images (Figure 4) showing the biomass growing with time. At time $t=22$ days, the membranes were colonized by diatoms. These results are consistent with those shown by Feng et al. (2016), who observed that the biofouling area was dominated by diatoms after 15 days deployment.

Figure 3 also shows that the biofilm growth was considerably higher on PES membranes from time $t=15$ days. This is explained by the presence of a larger number of diatoms, as seen in Figure 4. Standard deviations were high, showing that biofilm colonization was heterogeneous depending on the samples.

\subsection{Metal accumulation in the DGT}


PES membranes, no significant difference was observed between those DGTs equipped with both PES and PC membranes and DGTs equipped with PES membranes. Only the $\mathrm{Pb}$ accumulation pattern suggests a trend towards greater accumulation when DGTs were covered with PES membrane only (not statistically significant). Diatoms, which were more present on PES membranes, are phototrophic organisms that may lead to elevated $\mathrm{pH}$ inside the photosyntetically active biofilms (Liehr et al. 1994, Roeselers et al. 2008). This may favor removal of metals by precipitation. Here the metal accumulation by DGTs was not influenced by the phototrophic nature of the biofilms, except for $\mathrm{Pb}$ for which accumulation might be enhanced when diatoms are present.

$214 \mathrm{Cd}, \mathrm{Co}, \mathrm{Cu}, \mathrm{Mn}$, and $\mathrm{Ni}$ accumulations show a globally increasing trend between time $\mathrm{t}=0$ and time $\mathrm{t}=22$ 215 (Spearman's correlation tests between $\mathrm{m}$ and $\mathrm{t}$ : $\mathrm{p}$-values were respectively $5.10^{-6}, 3.10^{-8}, 7.10^{-11}, 3.10^{-8}, 7.10^{-15}$ ). 216 However, accumulation of $\mathrm{Cr}$ and $\mathrm{Pb}$ was less clear: the signal seems to remain stable because of the great 217 variability of the experimental points, even if they are all above the limit of detection LD (LD = average value of the 218 blanks $+3 \times$ standard deviation on the blanks, $n=8$ ). $\mathrm{Zn}$ accumulation increased between day 0 and day 3 , then seemed to increase from day 8 but the difference between day 8 and day 22 was not significant (Wilcoxon test, $\mathrm{p}=$ $0.09)$.

Replicates exhibited great variability (around 300\%). Several sources of uncertainty were highlighted by Knutsson et al. (2014) such as preparation, handling of the samplers, and the diffusional pathway. Here, after a long deployment time (22 days), the variability of the replicates remained unchanged. After such a long period of time, 224 the influence of blanks decreased significantly because of greater mass accumulation of metals. We thus assume that in situ conditions may play a role in the variability of the replicates, such as, for instance the position in the water column. We also noted that biomass greatly varied from one sample to another (Figure 3). Heterogeneous biofilm colonization may also explain the variability of the replicates.

228 The accumulation kinetics of DGTs deployed at time $\mathrm{t}=0$ were compared to accumulation kinetics built from the renewed DGTs, computed as follows: to calculate the average mass of metal at time $t=8$ days, the average mass of metal accumulated by DGTs between time $t=3$ and time $t=8$ days was added to the average mass of metal accumulated at time $t=3$, and so on until time $t=22$ days. Because no significant difference was observed between

232 DGTs equipped with both PES and PC membranes and DGTs equipped with PES membranes only, accumulation 233 kinetics were represented by the mean of all DGT replicates. Examples of $\mathrm{Co}, \mathrm{Cu}$, and $\mathrm{Zn}$ are presented in Figure 5 
234 while other metals are presented in the supporting information (see Figure SI-3). The kinetics built from renewed 235 DGTs clearly increased more linearly than the kinetics from DGTs deployed at time $t=0$ and are significantly 236 higher. A plateau was reached for all metals except Ni for DGTs deployed at time $t=0$. There was a substantial difference between the cumulated mass of renewed DGTs and the DGTs deployed for 22 days at the end of the deployment (on average 67\%).

Deployment conditions clearly affected the DGT measurement. We will now try to discuss what factors led to this difference between renewed and initial DGTs.

Two studies in the recent literature provide useful indications. Firstly, Mongin et al. (2013) studied the limits of the linear accumulation regime of DGTs and concluded that a low $\mathrm{pH}(<5)$, a high metal concentration, a long time, or a 243 high concentration of ligands can affect the linear regime of the DGTs. In the experiment reported in this article, $\mathrm{pH}$ 244 was around 8.46 and in favor of a linear regime. The metal concentrations in the Seine River were lower than $5.10^{-8}$ mol L $\mathrm{L}^{-1}$ for each metal while concentrations leading to a divergence of the linear regime in the study reported by 246 Mongin et al. (2013) were in the order of $10^{-3} \mathrm{~mol} \mathrm{~L}^{-1}$. Not more than 8 days were tested in the study of Mongin $e t$ al. (2013), so we are unable to draw conclusions on the time deployment. That being said if time affects the DGT measurement the $\mathrm{pH}$ conditions in the Seine River would argue more in favour of a linear regime.

249 Secondly, one significant characteristic of the Seine River is the calcium concentration (around $117 \mathrm{mg} \mathrm{L}^{-1} \approx 2.9$ mmol L ${ }^{-1}$ ). Tankéré-Muller et al. (2012) studied the effect of the competitive cation binding of metals by DGT in marine waters. They concluded that measurement of Mn, which has a weak affinity for Chelex 100 resin, was strongly affected by the competition with $\mathrm{Ca}^{2+}$ at $10 \mathrm{mmol} \mathrm{L}^{-1}$ (approximately a $25 \%$ decrease). However, Co, which was included as a control metal having a higher affinity for Chelex 100 than Mn, was much less affected (with a 254 deviation less than 10\%). In our study deviations exist for all metals including those having the best affinity for the resin $(\mathrm{Cu}, \mathrm{Pb}, \mathrm{Co})$ and are above $25 \%$. If the presence of relatively high concentrations of $\mathrm{Ca}^{2+}$ affect the DGT

256 measurement, especially for Mn, this does not fully explain the difference we observed in the Seine River. As well 257 as these parameters we suggest that biofouling may play a role in the decrease of the DGT measurement with respect to time. 


\subsection{Flux in the DGTs and biofilm effect}

262 The plot of flux in the DGTs with time shows that flux decreases for all metals (Figure 6 and Figure SI 4). If we 263 suppose that metal concentrations in water are relatively constant (except for $\mathrm{Cu}$ ), the flux should be constant. Here 264 we observe a sharp decrease during the first days of deployment, followed by a plateau at the end (Co, Zn), probably related to the plateaus observed for the metal accumulation in DGTs deployed at time $t=0$ (Figure 5). To verify the hypothesis that biofouling can affect the DGT measurement, we tried to fit the experimental data with the models described in the theoretical background. As no significant difference was observed between DGTs equipped with PES and PC membranes and DGTs equipped with PES membranes only, all the DGT replicates deployed at $\mathrm{t}=0$ were used to fit the model in order to improve the statistical power of the model.

The interaction model described by Equation 8 fits the data of DGTs deployed at $\mathrm{t}=0$ for Co and Zn very well with, respectively, $\mathrm{R}^{2}=0.78$ and 0.79 (Figure 6). The same pattern was observed for $\mathrm{Cd}, \mathrm{Mn}$, and $\mathrm{Ni}\left(\mathrm{R}^{2}=0.41,0.51,0.79\right.$; see SI). When fluxes of DGTs deployed later (at time $t=3,8$, and 15 days) are added to the graphs according to the deployment time, they fit the model for Co and Zn. However, they fit the model in a lesser extent for $\mathrm{Cd}, \mathrm{Mn}$ and $\mathrm{Ni}$ although replicates exhibit a great variability for these metals. This is in agreement with the hypothesis that concentrations were relatively constant for these metals during deployment. For them the fluxes depend more on the number of days DGTs were deployed rather than the moment where they were deployed. Regarding $\mathrm{Cu}$, the flux seems to decrease linearly with time and does not follow the nonlinear Equation 8. However, as we know, the $\mathrm{Cu}$ concentrations were not constant during the deployment and thus did not meet one of the assumptions of the model of Equation 8. We cannot therefore conclude about $\mathrm{Cu}$.

Moreover, $\mathrm{Cr}$ and $\mathrm{Pb}$ (see Figure SI 4) do not follow the model either. This could be related to the fact that accumulation of $\mathrm{Cr}$ was not significant enough for these elements (see Figure SI 2 and the section on metal accumulation), or else to the great variability of $\mathrm{Pb}$ replicates. Furthermore, other processes not taken into account in the model may occur.

In conclusion, the decrease of the metal flux in DGTs during deployment seems to be correctly defined by the metal-biofilm interaction model for $\mathrm{Cd}, \mathrm{Co}, \mathrm{Mn}, \mathrm{Ni}$, and $\mathrm{Zn}$. This model gives a suitable explanation as to why the biofouling effect on the measurement may depend on the metal and highlights the kinetic aspect of the biofouling 

involving MDL increase tested with our data (data not shown) were unsuccessful. A model combining both MDL increase and metal-biofilm interactions would be an issue, but requires more data than we had to correctly fit such a model.

\subsection{Kinetic constants and labile concentrations}

For $\mathrm{Cd}, \mathrm{Co}, \mathrm{Mn}, \mathrm{Ni}$, and $\mathrm{Zn}$, the parameters of the regression $J_{0}, \alpha$ and $\beta$ were estimated. From the latter, uptake and elimination rate constants $\mathrm{k}_{1}$ and $\mathrm{k}_{2}$ were calculated in $\mathrm{s}^{-1}$ and $\mathrm{d}^{-1}$ using Equation 10 and may be seen in Table 1, except $\mathrm{k}_{1}$ for $\mathrm{Cd}$ for which $\mathrm{C}_{\mathrm{W}}$ was under the limit of quantification. The characteristic time $\mathrm{t}_{1 / 2}$ corresponding to the time where the flux is equal to $50 \%$ of the initial flux was also calculated with

$\mathrm{t}_{1 / 2}=-\frac{1}{\beta} \ln \left(1-\frac{\mathrm{J}_{0}}{2 \alpha}\right)$

The initial labile concentration, which was not affected by biofouling, was calculated from $\mathrm{J}_{0}$ following Equation 11 :

$\mathrm{C}_{0}=\mathrm{J}_{0}\left(\frac{\Delta \mathrm{g}}{\mathrm{D}}+\frac{\mathrm{DBL}}{\mathrm{D}_{\mathrm{w}}}\right)$

$297 \mathrm{C}_{0}$ was compared with the mean dissolved concentration measured in water $\mathrm{C}_{\mathrm{W}}$ by calculating the $\mathrm{C}_{0} / \mathrm{C}_{\mathrm{W}}$ ratio. $\mathrm{C}_{0}$ 298 was consistent for $\mathrm{Cd}$ and was lower than the Cd labile concentrations found by Tusseau-Vuillemin et al. (2007) in 299 the Seine River. For $\mathrm{Co}$ and $\mathrm{Ni}, \mathrm{C}_{0}$ was lower than $\mathrm{C}_{\mathrm{W}}$, as can be expected from a labile concentration, and in the 300 range of values found by Tusseau-Vuillemin et al. The $\mathrm{C}_{0} / \mathrm{C}_{\mathrm{W}}$ ratio was also the same as in the Tusseau-Vuillemin et al. study for $\mathrm{Ni}$, but larger for $\mathrm{Co}$. In the case of $\mathrm{Mn}$ and $\mathrm{Zn}, \mathrm{C}_{0}$ was overestimated but was on the same order of magnitude as $\mathrm{C}_{\mathrm{W}}$.

$303 \mathrm{k}_{2}$ was in the same order of magnitude as $\mathrm{k}_{1}$. It illustrates that the biosorption mechanism is based on a number of 304 metal-binding processes taking place with components of the biofilm components' cell wall. The cell walls can reversibly biosorb metals and thus function in a similar way to an ion-exchange resin (Wase and Wase 2002). $\mathrm{k}_{2}$ 306 represents the dissociation of the metal from the biofilm, which is driven by the DGT gradient strength and must be higher to allow the accumulation of metal by Chelex resin (Co and Ni). The values of $\mathrm{k}_{1}$ calculated here are in the same order of magnitude as the water rate constant of $\mathrm{Cr}^{3+}\left(\mathrm{k}_{\mathrm{w}}=5.10^{-7} \mathrm{~s}^{-1}\right)$, which is considered to be very slow in comparison to the water rate constants of other metals $\left(\mathrm{k}_{\mathrm{w}}\left(\mathrm{Cd}^{2+}\right)=3.10^{8} \mathrm{~s}^{-1}, \mathrm{k}_{\mathrm{w}}\left(\mathrm{Co}^{2+}\right)=2.10^{6} \mathrm{~s}^{-1}\right)($ Stumm and Morgan 
311 of the predominant DGT gradient strength. However, some of the metal might be trapped. This is highlighted by the

312 calculation of the characteristic time $t_{1 / 2}$, presented in Table 1 , which shows that the flux is very quickly affected during the deployment and decreases within the first few days: in the case of Co, the flux was decreased by $50 \%$ in 314 just 4 days.

315 To obtain the $\mathrm{C}_{\mathrm{DGT}-\mathrm{m}}$, that is, the mean labile concentration of the metals in the Seine River that were the least 316 affected by in situ and physicochemical conditions, $\mathrm{C}_{\mathrm{DGT}}$ was derived from the slope of the accumulation kinetics of the renewed DGTs (See Figure 5) using Equation 12 (Tusseau-Vuillemin et al. 2007). The resulting labile concentrations are given in Table 2 . The labile concentration $\mathrm{C}_{\mathrm{DGT}-\mathrm{T} 22}$ calculated from the mass accumulated in DGTs at time $\mathrm{t}=22$ days using Equation 11 are also presented.

Labile concentrations from the renewed DGTs were in the same order of magnitude as the concentrations measured in the Seine River basin reported by Tusseau-Vuillemin et al. (2007) in which the deployment took 8 days. Labile percentages ranged from 21 to $202 \%$. It would be interesting to investigate $\mathrm{Mn}, \mathrm{Pb}$, and $\mathrm{Zn}$ in order to determine if the high value of $\mathrm{C}_{\mathrm{DGT}-\mathrm{m}}$ stems from possible contamination peaks that eluded the grab samples or raises questions regarding the technique and the calculations themselves.

The $\mathrm{C}_{\text {DGT-T22 }}$ was underestimated two- to sevenfold when compared with $\mathrm{C}_{\mathrm{DGT}-\mathrm{m}}$. This highlights the difference between that of a long deployment time affected as it is by environmental and physicochemical conditions and that of a shorter deployment time.

\section{Conclusion}

The quantitative model that has been proposed to highlight the biofouling effect was able to explain the decrease

330 observed on the flux toward the DGT resin of $\mathrm{Cd}, \mathrm{Co}, \mathrm{Mn}, \mathrm{Ni}$, and $\mathrm{Zn}$ on the presented data. Although other 331 processes not examined in this model may occur, the hypothesis that metals would be temporarily retained by the biofilm at the surface of the DGTs because of interactions within the biofilm is credible in the conditions of our study. In the conditions we studied we would recommend a deployment time of 5 to 8 days to minimize the

334 biofouling effect. However, biofouling is inevitable. The biofouling effect should certainly be considered as being a part of the in situ DGT response. Therefore in situ speciation results should be considered with care. 
336 However these kinetic processes may be dependent on the metal and the sampling site. Some strong effects observed

337 in our study may not happen in different conditions. More data in different conditions are needed to document

338 biofouling effect.

\section{ASSOCIATED CONTENT}

Supporting Information. Physicochemical parameters of the Seine River, the total dissolved concentration of metal in water and metal accumulation patterns in the DGTs during the deployment, accumulation kinetics in the DGTs, and the metal flux in the DGTs during the deployment are available as supporting information.

\section{AUTHOR INFORMATION}

\section{Corresponding Author}

345 * E-mail: emmanuelle.uher@irstea.fr; Tel: +33 1409665 39; Fax: +331 40966199.

\section{Funding Sources}

347 This study is part of the EMESTox project, funded by the French National Research Agency.

\section{Acknowledgments}

349 Sophie Ayrault (Laboratoire des Sciences du Climat et de l'Environnement, Gif-sur-Yvette, France) is

350 acknowledged for providing access to ICP-MS, as is Nicolas Gayet (Laboratoire Environnement Profond, Ifremer,

351 Brest) for his helpful technical support and expertise in total carbon measurements and SEM observations.

\section{References}

353 Booij K, van Bommel R, Mets A, Dekker R (2006): Little effect of excessive biofouling on the uptake of organic 354 contaminants by semipermeable membrane devices. Chemosphere 65, 2485-2492

355 Bradac P, Behra R, Sigg L (2009a): Accumulation of Cadmium in Periphyton under Various Freshwater Speciation 356 Conditions. Environ. Sci. Technol. 43, 7291-7296

357 Bradac P, Navarro E, Odzak N, Behra R, Sigg L (2009b): Kinetics of cadmium accumulation in periphyton under 

periphyton in a small stream with dynamic concentration variations. Environ. Pollut. 158, 641-648 G (2014): DGT-labile As, $\mathrm{Cd}, \mathrm{Cu}$ and Ni monitoring in freshwater: Toward a framework for interpretation of in situ deployment. Environ. Pollut. 192, 52-58

364 Davison W, Zhang H (2012): Progress in understanding the use of diffusive gradients in thin films (DGT) - back to basics. Environ. Chem. 9, 1-13

Duong TT, Morin S, Coste M, Herlory O, Feurtet-Mazel A, Boudou A (2010): Experimental toxicity and bioaccumulation of cadmium in freshwater periphytic diatoms in relation with biofilm maturity. Sci. Total Environ. $408,552-562$

Faburé J, Dufour M, Autret A, Uher E, Fechner LC (2015): Impact of an urban multi-metal contamination gradient: Metal bioaccumulation and tolerance of river biofilms collected in different seasons. Aquat. Toxicol. 159, $276-289$

Fechner LC, Gourlay-Francé C, Tusseau-Vuillemin MH (2014): Linking community tolerance and structure with 372 low metallic contamination: A field study on 13 biofilms sampled across the seine river basin. Water Res. 51, 152$373 \quad 162$

374 Feng ZM, Zhu P, Fan HT, Piao SS, Xu L, Sun T (2016): Effect of Biofilm on Passive Sampling of Dissolved Orthophosphate Using the Diffusive Gradients in Thin Films Technique. Anal. Chem. 88, 6836-6843

Garmo OA, Naqvi KR, Royset O, Steinnes E (2006): Estimation of diffusive boundary layer thickness in studies involving diffusive gradients in thin films (DGT). Anal. Bioanal. Chem. 386, 2233-2237

Garmo OA, Davison W, Zhang H (2008a): Effects of Binding of Metals to the Hydrogel and Filter Membrane on the Accuracy of the Diffusive Gradients in Thin Films Technique. Anal. Chem. 80, 9220-9225 
382 Ginisty P, Besnainou B, Sahut C, Guezennec J (1998): Biosorption of cobalt by Pseudomonas halodentrificans: 383 influence of cell wall treatment by alkali and alkaline-earth metals and ion-exchange mechanisms. Biotechnol. Lett. $384 \quad 20,1035-1039$

385 Hill WR, Larsen IL (2005): Growth dilution of metals in microalgal biofilms. Environ. Sci. Technol. 39, 1513-1518

386 Knutsson J, Rauch S, Morrison GM (2014): Estimation of Measurement Uncertainties for the DGT Passive Sampler 387 Used for Determination of Copper in Water. Int. J. Anal. Chem.

388 Kuyucak N, Volesky B (1988): Biosorbents for recovery of metals from industrial solutions. Biotechnology Letters $38910,137-142$

390 Landrum PF, Lee H, Lydy MJ (1992): Toxicokinetics in aquatic systems - model comparisons and use in hazard 391 assessment. Environ. Toxicol. Chem. 11, 1709-1725

392 Li W-W, Yu H-Q (2014): Insight into the roles of microbial extracellular polymer substances in metal biosorption. 393 Bioresour. Technol. 160, 15-23

394 Li Y, Gregory, S. (1974): Diffusion of ions in sea water and in deep-sea sediments. Geochim. Cosmochim. Acta 38, $395 \quad 703-714$

396 Liehr SK, Chen H-J, Lin S-H (1994): Metals removal by algal biofilms. Water Sci. Technol. 30, 59-68

397 Mongin S, Uribe R, Rey-Castro C, Cecilia J, Galceran J, Puy J (2013): Limits of the Linear Accumulation Regime 398 of DGT Sensors. Environ. Sci. Technol. 47, 10438-10445

399 Moppert X, Le Costaouec T, Raguenes G, Courtois A, Simon-Colin C, Crassous P, Costa B, Guezennec J (2009): 400 Investigations into the uptake of copper, iron and selenium by a highly sulphated bacterial exopolysaccharide 401 isolated from microbial mats. J. Ind. Microbiol. Biotechnol. 36, 599-604

402 More TT, Yadav JSS, Yan S, Tyagi RD, Surampalli RY (2014): Extracellular polymeric substances of bacteria and 403 their potential environmental applications. J. Environ. Manage. 144, 1-25 
404 Nimick DA, Gammons CH, Parker SR (2011): Diel biogeochemical processes and their effect on the aqueous chemistry of streams: A review. Chem. Geol. 283, 3-17

Pichette C, Zhang H, Davison W, Sauve S (2007): Preventing biofilm development on DGT devices using metals and antibiotics. Talanta 72, 716-722

Roeselers G, Loosdrecht MCMv, Muyzer G (2008): Phototrophic biofilms and their potential applications. J. Appl. Phycol. 20, 227-235

Schafer RB, Paschke A, Liess M (2008): Aquatic passive sampling of a short-term thiacloprid pulse with the

411 Chemcatcher: Impact of biofouling and use of a diffusion-limiting membrane on the sampling rate. J. Chromatogr. A $4121203,1-6$

413 Stumm W, Morgan J (1996): Aquatic geochemistry. Chemical Equilibria and Rates in Natural Waters, A Wiley414 Interscience Publication, New York

415 Tankere-Muller S, Davison W, Zhang H (2012): Effect of competitive cation binding on the measurement of Mn in 416 marine waters and sediments by diffusive gradients in thin films. Anal. Chim. Acta 716, 138-144

417 Toner B, Manceau A, Marcus MA, Millet DB, Sposito G (2005): Zinc sorption by a bacterial biofilm. Environ. Sci. 418 Technol. 39, 8288-8294

419 Tusseau-Vuillemin MH, Gourlay C, Lorgeoux C, Mouchel JM, Buzier R, Gilbin R, Seidel JL, Elbaz-Poulichet F 420 (2007): Dissolved and bioavailable contaminants in the Seine river basin. Sci. Total Environ. 375, 244-256

421 Uher E, Zhang H, Santos S, Tusseau-Vuillemin M-H, Gourlay-Francé C (2012): Impact of Biofouling on Diffusive 422 Gradient in Thin Film Measurements in Water. Anal. Chem. 84, 3111-3118

423 Uher E, Tusseau-Vuillemin MH, Gourlay-Francé C (2013): DGT measurement in low flow conditions: diffusive 424 boundary layer and lability considerations. Env. Sci. Process. Impact 15, 1351-1358

425 Van Hullebusch ED, Zandvoort MH, Lens PN (2003): Metal immobilisation by biofilms: Mechanisms and 426 analytical tools. Rev. Environ. Sci. Bio/Technol. 2, 9-33 
427 Veglio F, Beolchini F (1997): Removal of metals by biosorption: A review. Hydrometallurgy 44, $301-316$

428 Warnken KW, Zhang H, Davison W (2006): Accuracy of the diffusive gradients in thin-films technique: Diffusive

429 boundary layer and effective sampling area considerations. Anal. Chem. 78, 3780-3787

430 Wase DAJ, Wase J (2002): Biosorbents for Metal Ions. CRC Press

431 White C, Gadd GM (2000): Copper accumulation by sulfate-reducing bacterial biofilms. FEMS Microbiol. Lett.

$432183,313-318$

433 Zhang H, Davison W (1995): Performance-Characteristics of Diffusion Gradients in Thin-Films for the in-Situ

434 Measurement of Trace-Metals in Aqueous-Solution. Anal. Chem. 67, 3391-3400

435

436

437 


\section{In situ measurement with diffusive gradients in}

\section{thin films: effect of biofouling in freshwater}

Emmanuelle Uher ${ }^{* 1,2}$, Chantal Compère ${ }^{3}$, Matthieu Combe ${ }^{1}$, Florence Mazeas ${ }^{3}$, Catherine Gourlay-Francé $\dagger^{1,2}$.

Figures and tables

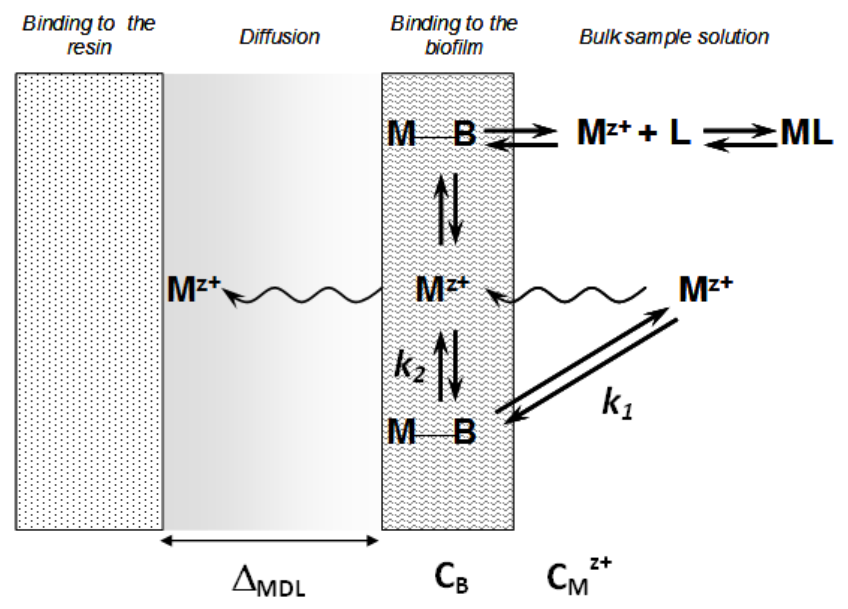

Figure 1- Schematic representation of the role of the biofilm in the accumulation of metal by DGT (adapted from Uher et al. 2011) 


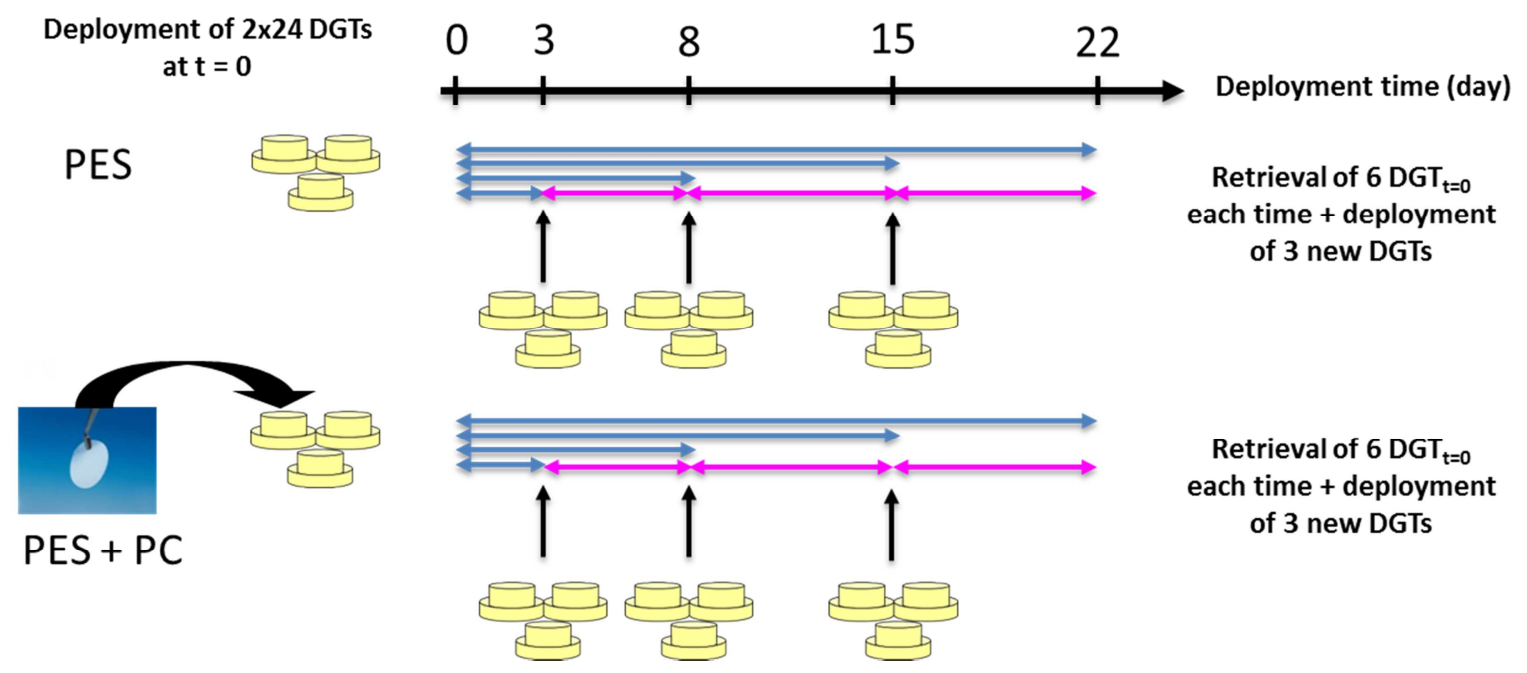

Figure 2 - Deployment scheme of the DGTs in the Seine River

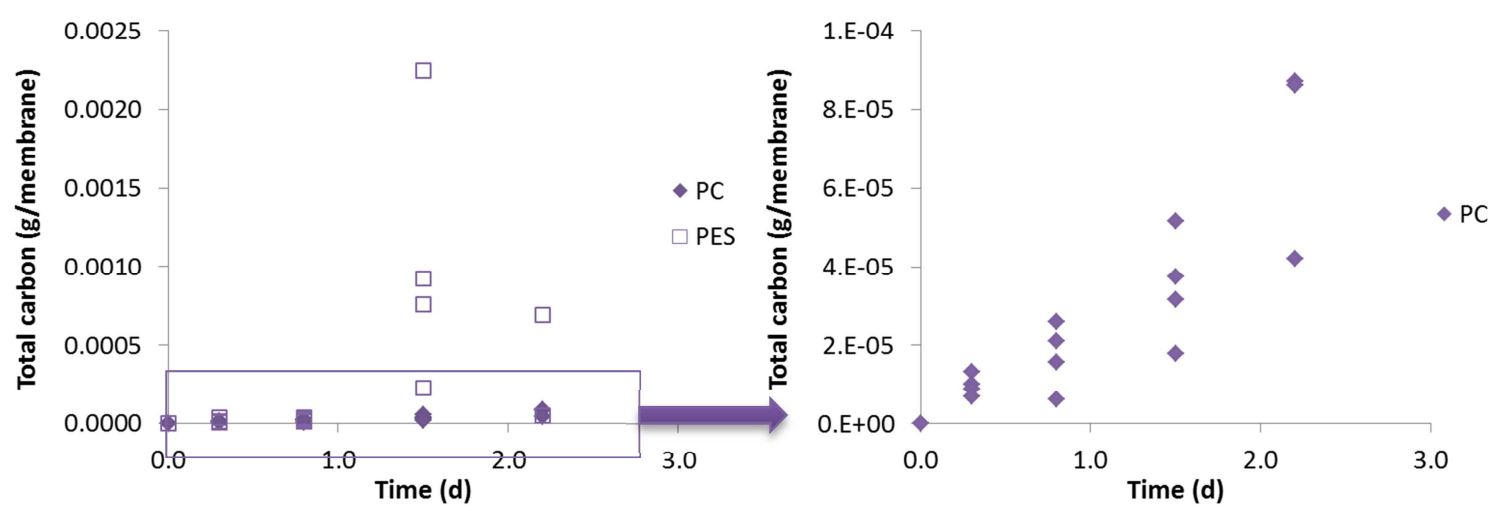

Figure 3 - Total carbon per membrane over time 


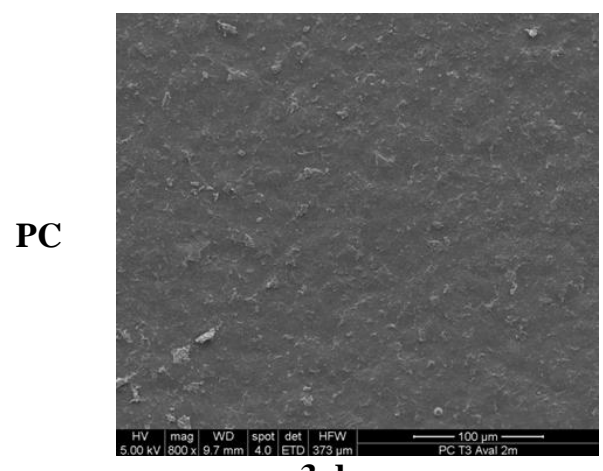

3 days

PES

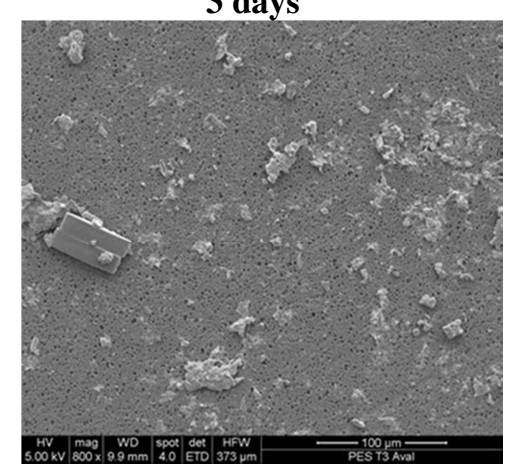

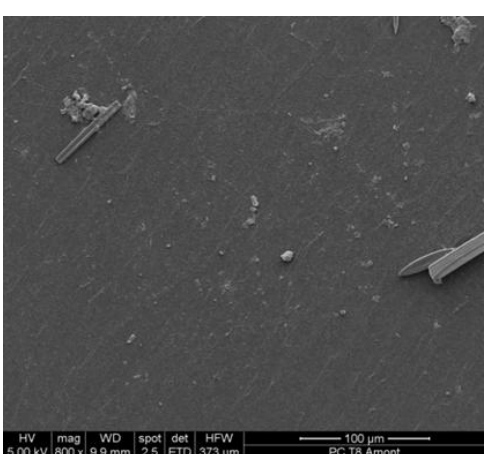

8 days

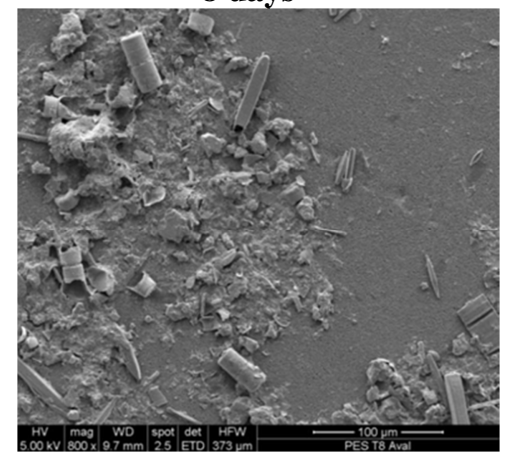

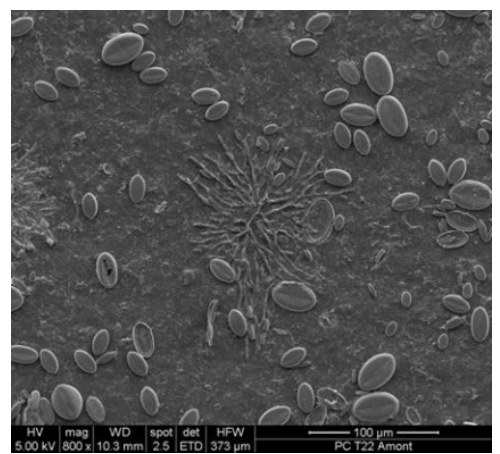

22 days

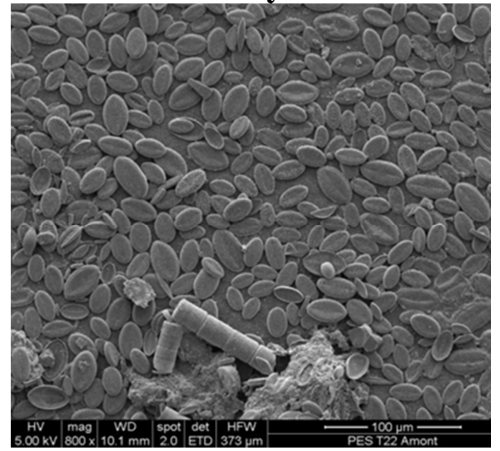

Figure 4 - SEM pictures of the biofilm attached to the membranes over time 
Co

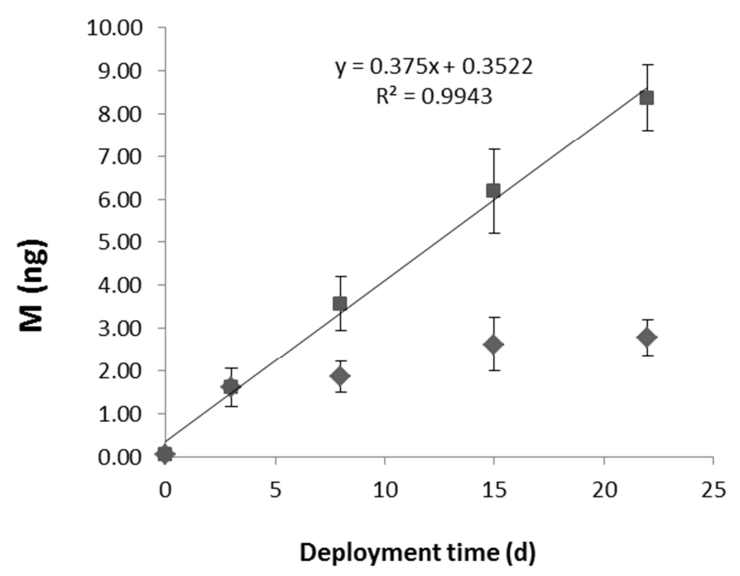

$\mathrm{Zn}$

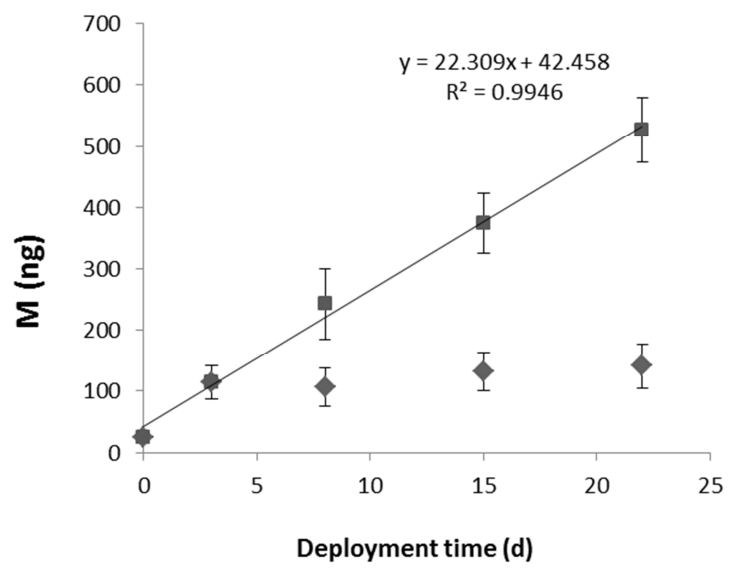

$\mathrm{Cu}$

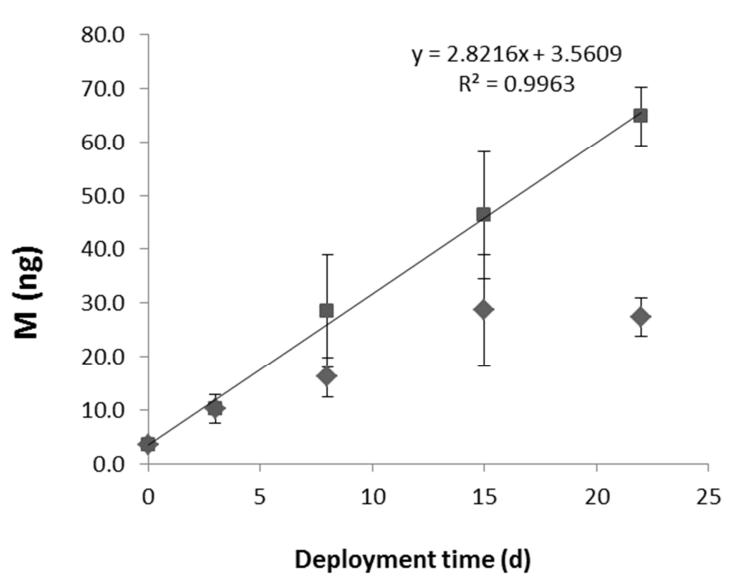

Figure 5 - Accumulation kinetics in all the DGTs deployed at $\mathbf{t}=\mathbf{0}$ and in all the renewed DGTs. Bars represent standard deviations. 

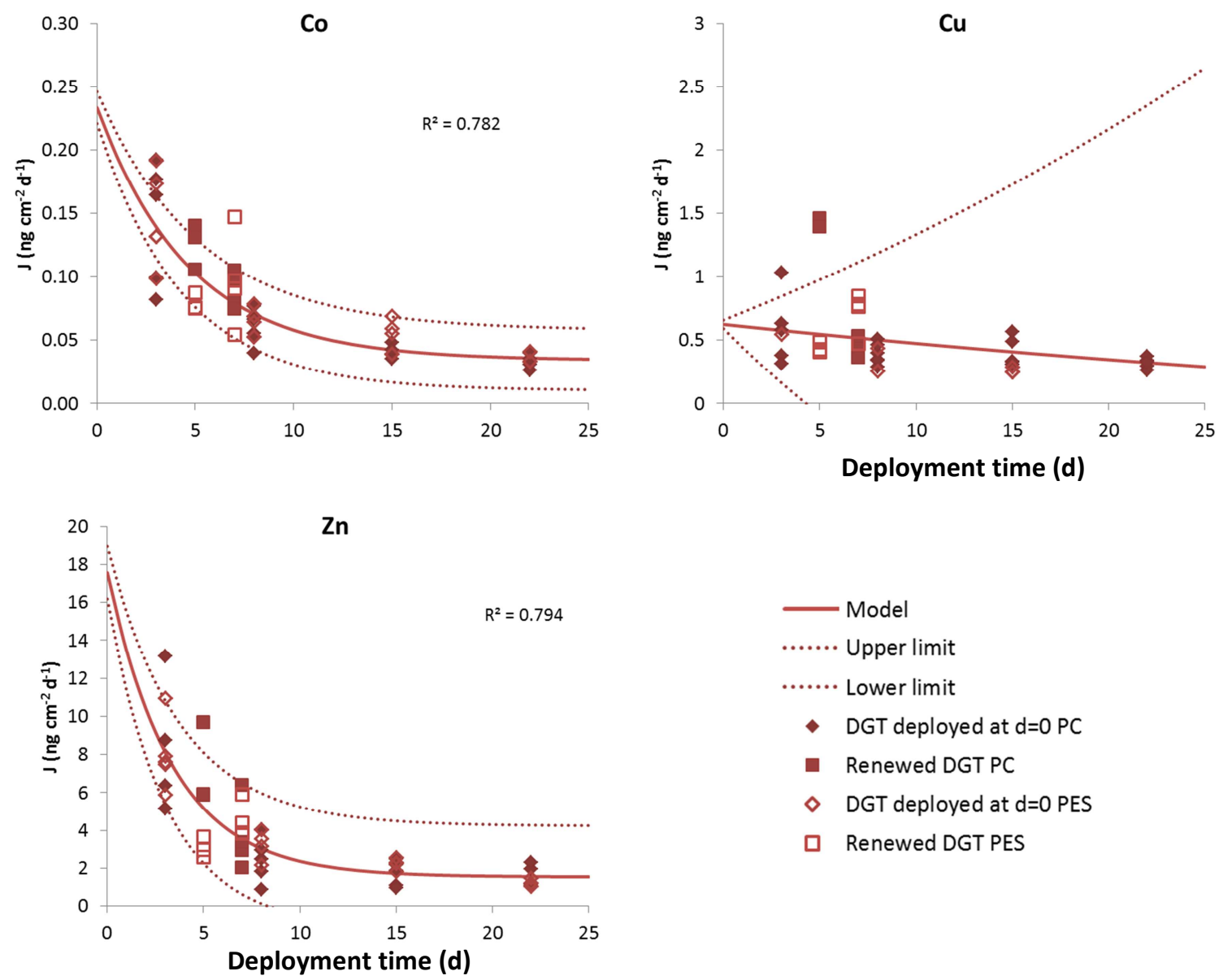

Figure 6 - Metal flux in the DGTs during the deployment and model fitting the data of DGTs deployed at $\mathrm{d}=0$ and including PES and PC. DGTs deployed at $\mathrm{t}=\mathbf{0}$ are represented by diamonds. Open symbols represent DGTs equipped with PES membranes, and filled symbols represent DGTs equipped with PC membranes. Upper and lower limits were calculated with the minima and maxima values of the parameters confidence intervals. 


\begin{tabular}{|c|c|c|c|c|c|}
\hline & Cd & Co & Mn & $\mathrm{Ni}$ & $\mathbf{Z n}$ \\
\hline$J_{0}\left(n g \mathrm{~cm}^{-2} \mathrm{~s}^{-1}\right)$ & $1.10 \times 10^{-7}$ & $2.67 \times 10^{-6}$ & $1.70 \times 10^{-4}$ & $2.27 \times 10^{-5}$ & $2.00 \times 10^{-4}$ \\
\hline $\begin{array}{l}C_{0}\left(\mu g L^{-1}\right) \\
\left(\% C_{0} / C_{W}\right)\end{array}$ & $\begin{array}{c}0.0045 \\
\text { n.c }\end{array}$ & $\begin{array}{c}0.11 \\
(60 \%)\end{array}$ & $\begin{array}{c}6.8 \\
(319 \%)\end{array}$ & $\begin{array}{c}0.93 \\
(46 \%)\end{array}$ & $\begin{array}{c}6.8 \\
(308 \%)\end{array}$ \\
\hline $\begin{array}{c}k_{1}\left(s^{-1}\right) \\
\left(d^{-1}\right)\end{array}$ & $\begin{array}{l}\text { n.c } \\
\text { n.c }\end{array}$ & $\begin{array}{c}1.11 \times 10^{-6} \\
0.096\end{array}$ & $\begin{array}{c}4.06 \times 10^{-6} \\
0.35\end{array}$ & $\begin{array}{c}7.92 \times 10^{-7} \\
0.068\end{array}$ & $\begin{array}{c}8.29 \times 10^{-6} \\
0.72\end{array}$ \\
\hline $\begin{array}{c}k_{2}\left(s^{-1}\right) \\
\left(d^{-1}\right)\end{array}$ & $\begin{array}{c}1.33 \times 10^{-6} \\
0.11\end{array}$ & $\begin{array}{c}2.45 \times 10^{-6} \\
0.21\end{array}$ & $\begin{array}{c}1.84 \times 10^{-6} \\
0.16\end{array}$ & $\begin{array}{c}2.46 \times 10^{-6} \\
0.21\end{array}$ & $\begin{array}{c}3.43 \times 10^{-6} \\
0.30\end{array}$ \\
\hline$t_{1 / 2}(d)$ & 9.0 & 4.1 & 6.4 & 4.5 & 2.7 \\
\hline
\end{tabular}

Table 1. Initial flux, initial labile concentration, uptake, and elimination rate of the metal in the biofilm and half-time of the flux calculated from the parameters of the nonlinear regression.

\begin{tabular}{|ccccccccc|} 
& $\mathbf{C d}$ & $\mathbf{C r}$ & $\mathbf{C o}$ & $\mathbf{C u}$ & $\mathbf{M n}$ & $\mathbf{N i}$ & $\mathbf{P b}$ & $\mathbf{Z n}$ \\
\hline $\boldsymbol{C}_{\boldsymbol{D G T - m}}\left(\boldsymbol{\mu g} \boldsymbol{L}^{-1}\right)$ & 0.0049 & 0.21 & 0.048 & 0.34 & 4.3 & 0.44 & 0.25 & 2.4 \\
$\left(\boldsymbol{\%} \boldsymbol{C}_{\boldsymbol{D G T}} / \boldsymbol{C}_{\boldsymbol{W}}\right)$ & n.c & $(33 \%)$ & $(27 \%)$ & $(29 \%)$ & $(202 \%)$ & $(21 \%)$ & $(183 \%)$ & $(108 \%)$ \\
\hline $\boldsymbol{C}_{\boldsymbol{D G T - T 2 2}}\left(\boldsymbol{\mu} \boldsymbol{g} \boldsymbol{L}^{-1}\right)$ & 0.0020 & 0.058 & 0.016 & 0.15 & 1.6 & 0.19 & 0.034 & 0.68 \\
$\left(\boldsymbol{\%} \boldsymbol{C}_{\boldsymbol{D G T}} / \boldsymbol{C}_{\boldsymbol{W}}\right)$ & n.c & $(9 \%)$ & $(9 \%)$ & $(13 \%)$ & $(74 \%)$ & $(10 \%)$ & $(25 \%)$ & $(31 \%)$ \\
\hline
\end{tabular}

Table 2. Labile concentration calculated from accumulation kinetics of the renewed DGTs and labile concentrations calculated from mass accumulated at $t=22$ days. Labile percentage in relation to the dissolved concentration in parentheses 
SUPPORTING INFORMATION

\begin{tabular}{|c|c|c|c|c|c|c|c|c|c|c|c|c|}
\hline & $\mathbf{p H}$ & $\mathbf{T}^{\mathbf{0}}$ & $\mathrm{Ca}^{2+}$ & $\mathbf{K}^{+}$ & $\mathbf{M g}^{2+}$ & $\mathrm{Na}^{+}$ & $\mathrm{Cl}^{-}$ & $\mathbf{N O}_{3}^{-}$ & $\mathbf{P O}_{4}{ }^{3-}$ & $\mathbf{S O}_{4}{ }^{2-}$ & $\mathbf{C O}_{3}{ }^{2-}$ & $\mathbf{D O C}$ \\
\hline Units & - & ${ }^{\circ} \mathrm{C}$ & $\mathrm{mg} \mathrm{L}^{-1}$ & $\mathrm{mg} \mathrm{L}^{-1}$ & $\mathrm{mg} \mathrm{L}^{-1}$ & $\mathrm{mg} \mathrm{L}^{-1}$ & $\mathrm{mg} \mathrm{L}^{-1}$ & $\mathrm{mg} \mathrm{L}^{-1}$ & $\mathrm{mg} \mathrm{L}^{-1}$ & $\mathrm{mg} \mathrm{L}^{-1}$ & $\mathrm{mg} \mathrm{L}^{-1}$ & $\mathrm{mg} \mathrm{L}^{-1}$ \\
\hline Mean & 8.46 & 13.09 & 117.0 & 2.356 & 2.33 & 10.5 & 19.1 & 21.85 & n.d & 22.48 & 266 & 2.48 \\
\hline Cl 95\% & 0.13 & 0.79 & 9.2 & 0.087 & 0.17 & 1.7 & 2.8 & 0.51 & n.d & 0.92 & 20 & 0.31 \\
\hline
\end{tabular}

Table SI 1 - Physicochemical parameters of the Seine River during the deployment. Concentrations are the mean of 6 $\left(\mathrm{Ca}^{2+}, \mathrm{K}^{+}, \mathrm{Mg}^{2+}, \mathrm{Na}^{+}, \mathrm{Cl}^{-}, \mathrm{NO}_{3}^{-}, \mathrm{SO}_{4}{ }^{2-}\right), 8\left(\mathrm{~T}^{\circ}\right)$ and $9\left(\mathrm{CO}_{3}{ }^{2-}, \mathrm{DOC}, \mathrm{pH}\right)$ grab samples. $\mathrm{n} . \mathrm{d}=$ not detected. $\mathrm{Cl}$ : confidence interval $95 \%$ 

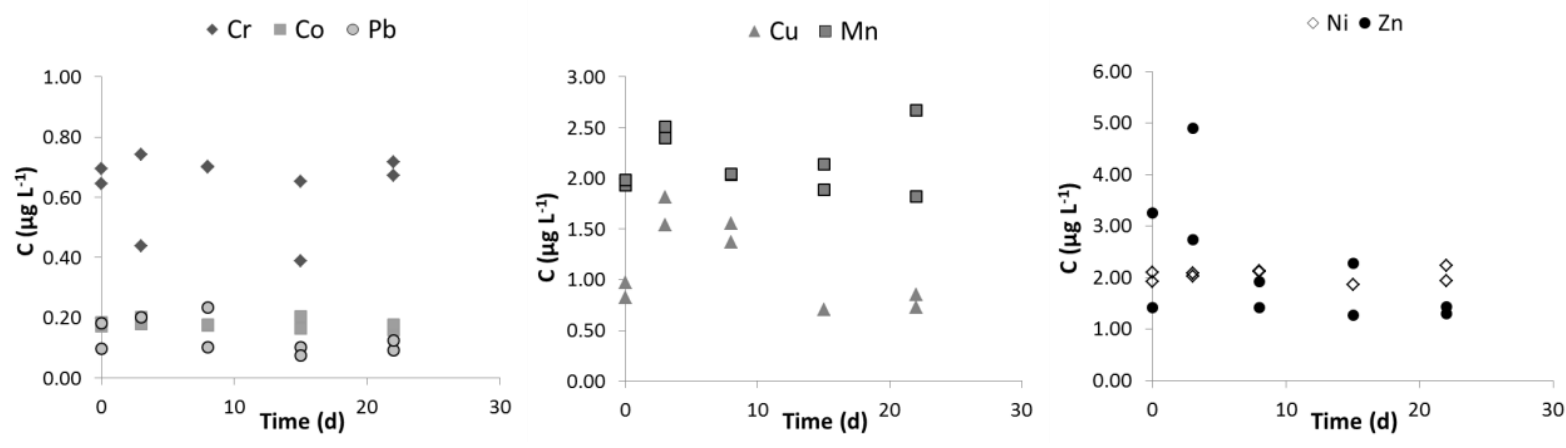

Figure SI 1 - Total dissolved concentration in $\mu \mathrm{g} \mathrm{L}^{-1}$ during the deployment 
Cd

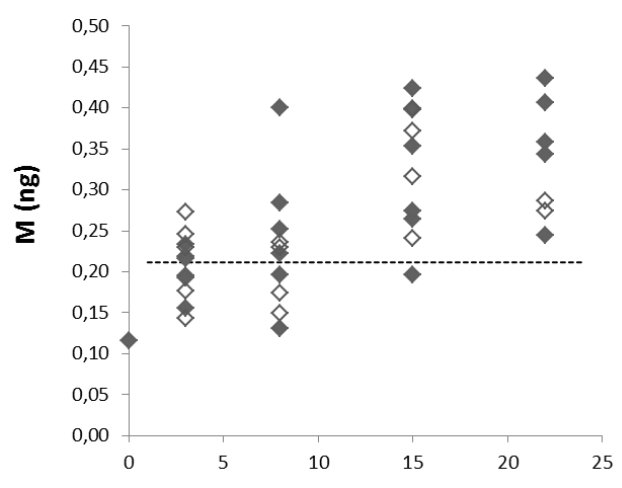

Co

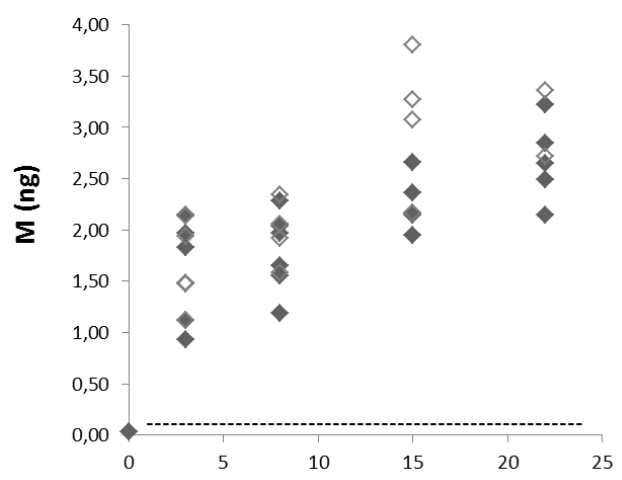

Mn

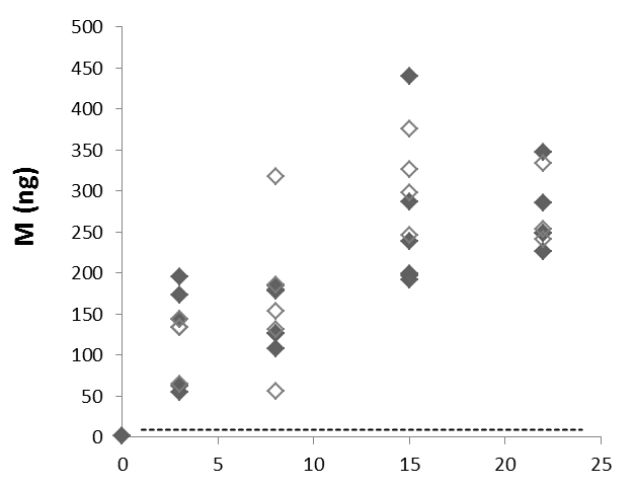

$\mathrm{Pb}$

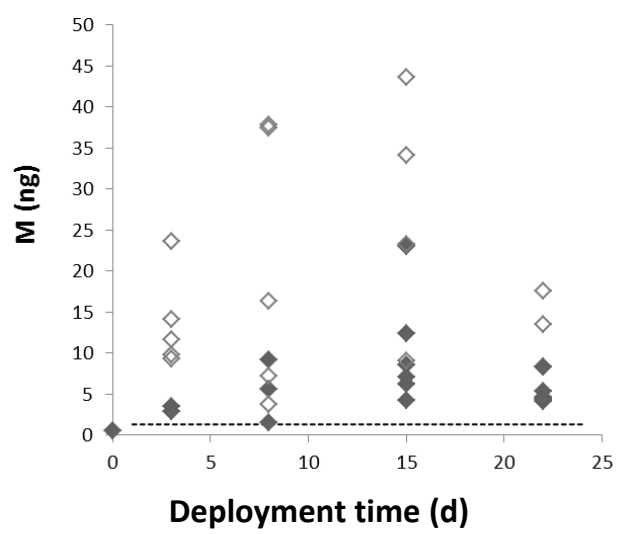

$\mathrm{Cr}$

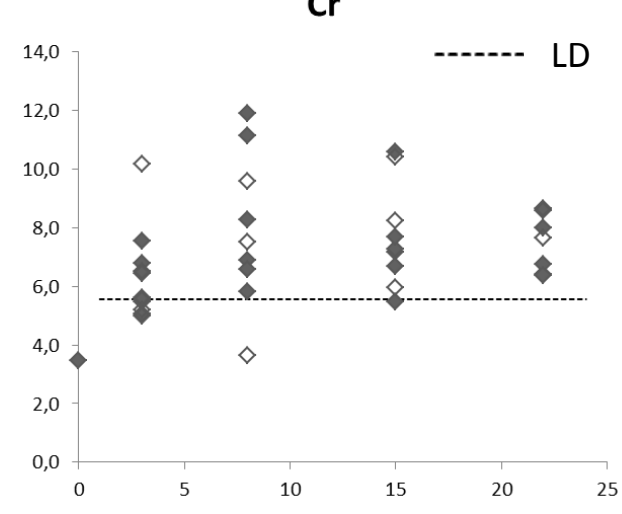

$\mathrm{Cu}$

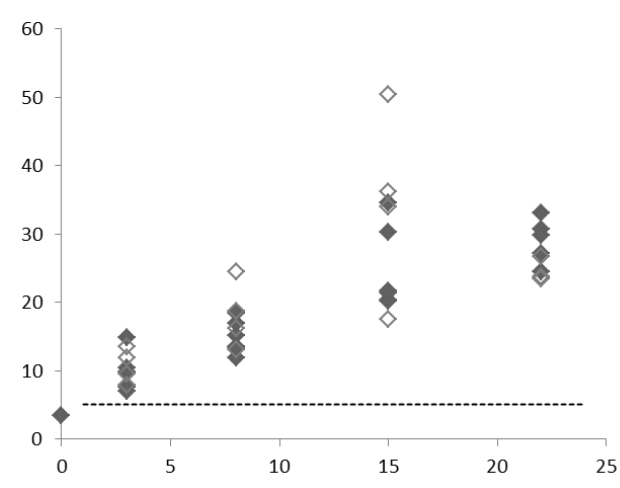

Ni

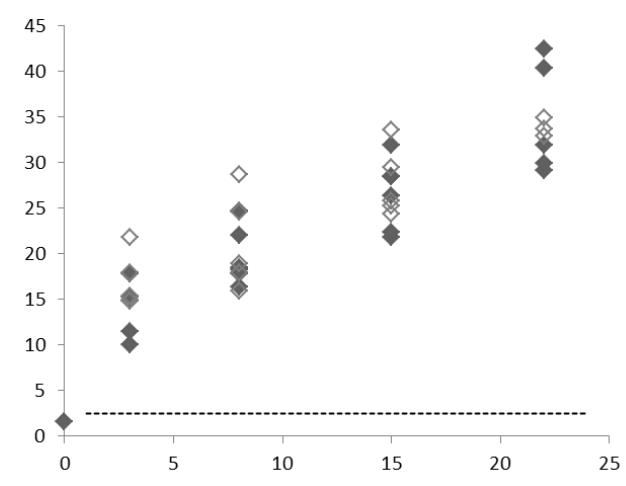

Zn

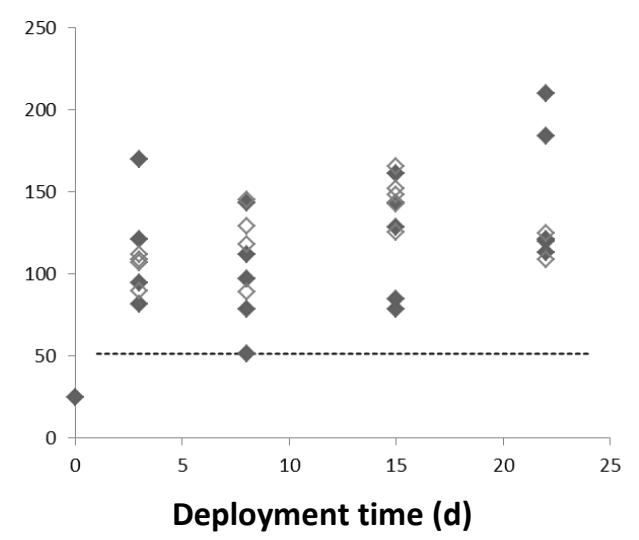

Figure SI 2 - Metal accumulation patterns in the DGTs during the deployment. Open symbols: DGTs equipped with PES membranes. Closed symbols: DGTs equipped with PES+PC membranes 
Cd

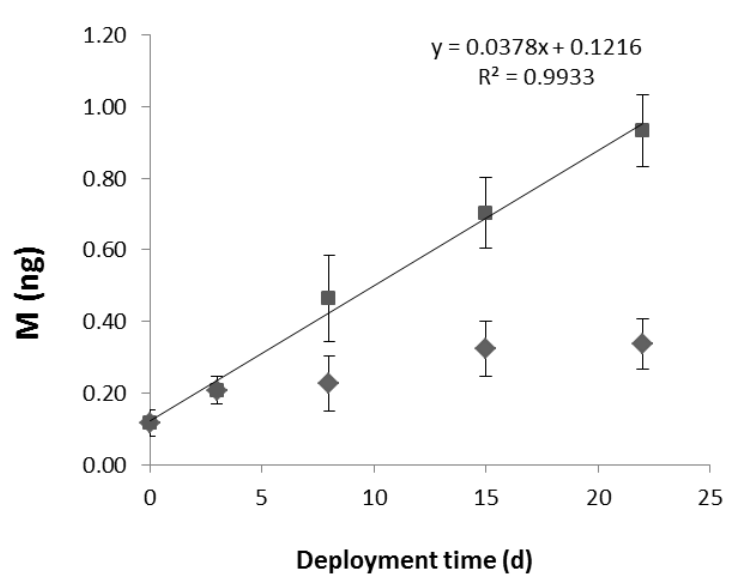

$\mathrm{Mn}$

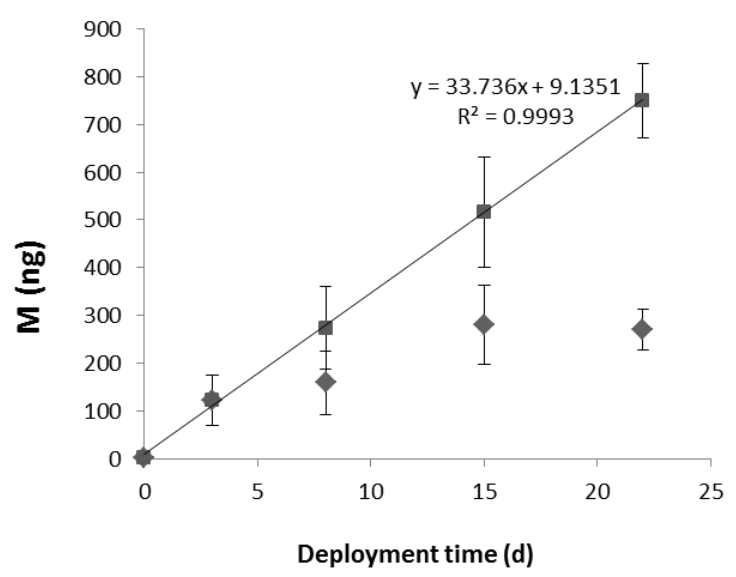

$\mathrm{Pb}$

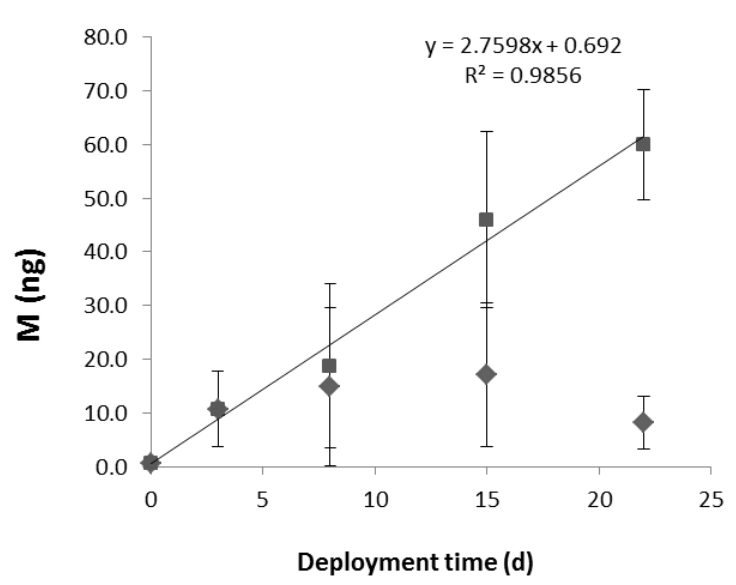

$\mathrm{Cr}$

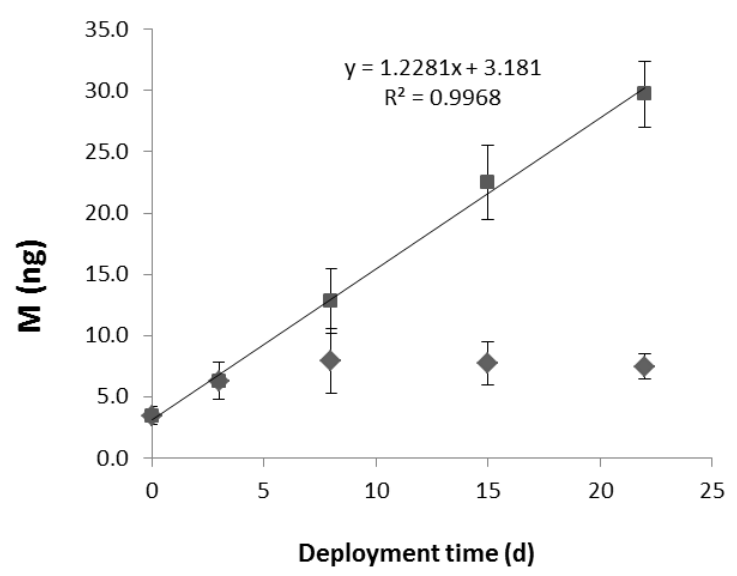

$\mathrm{Ni}$

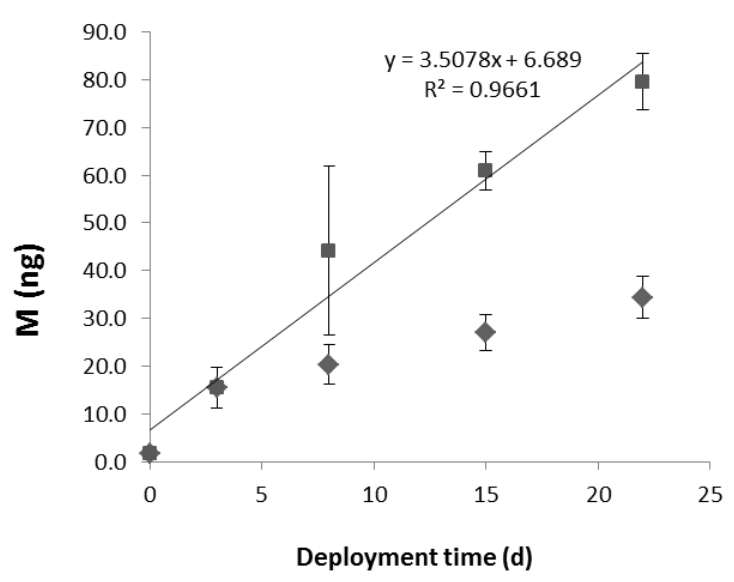

Figure SI 3 - Accumulation kinetics in all the DGTs deployed at $\mathbf{d}=\mathbf{0}$ and in all the renewed DGTs. Bars represent standard deviations. 

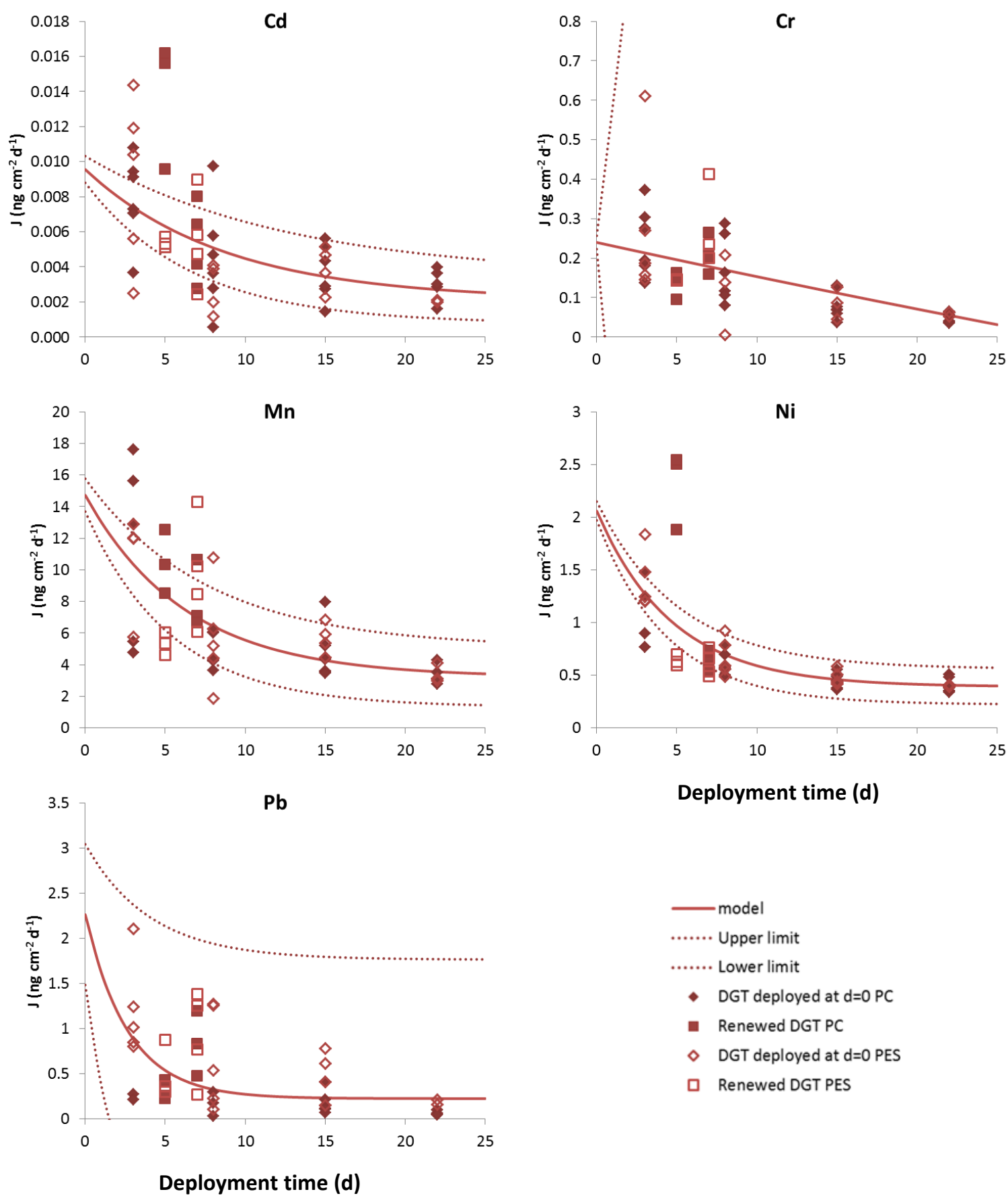

Deployment time (d)

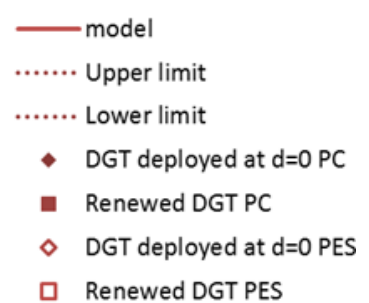

Figure SI 4 - Metal flux in the DGTs during the deployment and model fitting the data of DGTs deployed at $\mathbf{d}=\mathbf{0}$ and including PES and PC. Upper and lower limits were calculated with the minima and maxima values of the parameters confidence intervals. 